\title{
U.S. healthcare providers' knowledge, attitudes, beliefs, and perceptions concerning Chronic Fatigue Syndrome
}

\author{
Dana J Brimmer*1, Frederick Fridinger ${ }^{2}$, Jin-Mann S Lin ${ }^{1}$ and William C Reeves ${ }^{1}$
}

\begin{abstract}
Background: Chronic fatigue syndrome (CFS) is a debilitating illness with particular difficulties for healthcare providers because there are no diagnostic signs or laboratory tests and because management aims to merely improve symptoms. Further complicating management, healthcare providers' awareness concerning CFS has not been rigorously assessed. The present study aimed to ascertain United States (U.S.) healthcare providers' awareness of CFS and to assess their knowledge, attitudes, and beliefs (KAB) related to diagnosis and management of the illness. This information forms the foundation for developing CFS educational strategies.

Methods: We combined convenience and probability samples to measure CFS KAB among healthcare providers. In the convenience sample, 1,255 healthcare providers ( $81 \%$ response rate) from 13 professional conferences completed a 12-item form. Descriptive statistics were reported for 9 KAB item responses and chi-square tests were performed for examining their association with giving a diagnosis of CFS. We used principal component analysis to construct multidimensional subscales and perform a general linear model to examine factors associated with subscales. The probability sample involved data on 15 CFS-specific questions from 2006 and 2007 DocStyles web-based panel surveys collected from 2,750 physicians (average response rate 55\%). We calculated descriptive and chi-square statistics. The significance was set at two-tailed with the alpha level of 0.05 .
\end{abstract}

Results: Healthcare providers in both samples were aware of CFS and exhibited a high level of knowledge. Overall, 96\% of respondents in the DocStyles (probability) sample had heard about CFS. Healthcare providers in the conference (convenience) sample demonstrated good KAB scores; physicians' scores were highest on KAB scales and lowest in perception. Nurses' scores were lowest in knowledge. More than $40 \%$ of physicians reported ever giving a CFS diagnosis and in the DocStyles (probability) sample more than $80 \%$ of physicians correctly identified CFS symptoms. Physicians reported professional journals, the Internet, and continuing education programs as the top 3 sources from which they obtain CFS information.

Conclusions: Findings from these combined samples fill a gap in the evidence-base of U.S. healthcare providers' and knowledge, attitudes, and beliefs concerning CFS. Importantly, respondents in both samples expressed similar knowledge, attitudes, beliefs and perceptions. Awareness was high and negative attitudes were low. The primary areas for future education should address diagnosis and management of CFS and should be delivered through those venues providers indicated they primarily use. Data from this study provide a benchmark for evaluation the success of these future efforts.

\section{Background}

Chronic fatigue syndrome (CFS) is a debilitating illness [1] that presents unique difficulties for healthcare provid-

*Correspondence: dyv4@cdc.gov

1 Division of Viral and Rickettsial Diseases, Centers for Disease Control and Prevention, Atlanta, GA, USA

Full list of author information is available at the end of the article ers because there are no diagnostic signs, laboratory abnormalities or biomarkers and management aims to improve symptoms; no definitive therapy has been identified. Adding to this, the symptoms comprising CFS are similar to those of many medical illnesses, which must be ruled out $[2,3]$. Patients with CFS often require multiple 
office visits and insurance may not cover associated evaluations and lab tests. Further complicating diagnosis and management, some patients perceive skepticism or lack of awareness concerning CFS as a legitimate illness among providers (in particular physicians), which can lead to mistrust and a challenge to patients identity $[4,5]$. Finally, psychiatric comorbidities (e.g., depression) are common among CFS patients [6] and this poses additional challenges for healthcare providers [3,7].

These problems may in large part explain why only $50 \%$ of individuals with CFS have consulted a physician for their illness and fewer than $20 \%$ of people with CFS have been diagnosed and treated for the illness $[8,9]$. Educating providers concerning CFS should improve identification, diagnosis, and management of CFS, but educational activities must be based on providers' current knowledge, attitudes, and beliefs in order to target major current weaknesses. Knowledge, attitudes, and beliefs (KABs) have been studied in the United Kingdom (U.K.), the Netherlands, and Australia, but research in the United States (U.S.) is limited. In the U.K., Raine et al report that primary care physicians feel uncertain or dismissive of CFS, and that these perceptions may pose a barrier to illness management [10]. A separate study reported that despite recent guidelines on CFS management in the U.K. and positive attitudes towards CFS, only $72 \%$ of physicians recognized CFS clinically [11]. Bowen et al also reported that $49 \%$ of physicians identified the clinical hallmarks of CFS, yet knowledge was not a factor in the self-efficacy of giving a diagnosis [11]. Thomas and Smith found $56 \%$ of general practitioners believed CFS as an illness and of this group, $67 \%$ reported giving a diagnosis of CFS [12].

In the Netherlands, Scheeres et al showed that physicians informed about CFS reported higher levels of knowledge and better attitudes towards the illness [13]. And, in the same study physicians receiving CFS education were significantly more likely to refer patients for cognitive behavioral therapy compared to physicians who did not receive education [13]. In Australia, 27\% of practitioners reported that they did not believe CFS as a syndrome, and yet $71 \%$ of the sample stated they had treated a patient for CFS [14]. This study also found that practitioners, who were younger, female, and practiced in small settings, were significantly more likely to accept CFS as an illness. Steven and colleagues state that practitioners who acknowledged CFS as a distinct illness reported more accurate knowledge of CFS (e.g., diagnostic characteristics) and identified appropriate management strategies [14]. One study in the United States did examine attitudes towards treating CFS patients in medical students. However, the study population and small sample size inhibit generalizability to physician populations [15].
We examined KABs about CFS among physicians and other healthcare providers from two different populations in the United States. Our research had three objectives: 1) ascertain awareness of CFS among healthcare providers; 2) assess the knowledge, attitudes, and beliefs related to CFS diagnosis and treatment, and 3) determine where physicians obtain information regarding CFS.

\section{Methods}

We used convenience and probability sampling methods separately on two different populations regarding knowledge, attitudes, and beliefs concerning CFS by healthcare providers in the United States. In the first sample, we queried a convenience sample of healthcare providers from 13 national-level provider conferences around the country between February 2006 and October 2007. Conferences focused on physicians, nurse practitioners, physician assistants, nurses, or allied health providers and conference size ranged from 1,410 to 7,900 attendees. We staffed a CDC-sponsored CFS education booth in the conference exhibit hall, and for each conference an exhibit booth fee was paid per industry standard. For all conferences we advertised the CFS education booth through advertisements in conference programs, preevent mailers, and partial conference sponsorships. The education booth displayed and provided free CFS materials such as journal articles, management guidelines, and reference bibliographies and also offered access to free CFS CME courses.

As part of the exhibit, a limited number (75-100 per conference) of USB sticks with CFS educational information were made available to conference participants on a "first-come, first-serve basis." The numbers of USB sticks per conference were decided a priori. In exchange for a USB stick, and to help evaluate the awareness booth activities, conference attendees were asked, but not required, to fill out an anonymous, one-page 12-item CFS KAB form. No identifying information was collected. Permission to dispense USB sticks and collect KAB information was granted by conference organizers and this follows a standard approach used by conference exhibitors.

Content validity of the KAB form was assessed from a pool of questions derived from a panel of experts in CFS research. It included 9 items preliminarily assessing CFS knowledge, attitudes, and beliefs, and 3 questions asking "Have you ever given a diagnosis of chronic fatigue syndrome" (yes, no, or not applicable); "Type of setting do you practice in" (hospital, private practice, group practice, academic, community, or other); and "Type of degree" (doctor of medicine (MD), doctor of osteopathic medicine (DO), nurse practitioner (NP), physician's assistant (PA), registered nurse (RN), occupational therapist (OT), doctor of philosophy (PhD), Masters degree, and other). 
Respondents could identify more than one practice setting and degree.

Descriptive statistics were reported for the $9 \mathrm{KAB}$ item responses and chi-squared tests were performed to examine their association with giving a diagnosis of CFS. We also analyzed the KAB questions by using exploratory principal components analysis with a varimax rotation. Both a theoretical basis and Suhr's recommendations (variables on same factors share conceptual meanings and variables on different factors differ conceptually) guided variable selection and interpretation of factors [16]. We chose to keep items greater than 0.40 for each factor. The nine KAB questions were measured on scale ranging from $1=$ strongly disagree and $7=$ strongly agree. A general linear model examined the associations of $\mathrm{KAB}$ scales with the factors, CFS diagnosis, practice setting, and type of degree.

In the second sample, probability sampling method was employed through DocStyles, a survey conducted by Porter Novelli (a CDC contractor) in July and August 2006 and 2007. DocStyles is a web-based panel survey developed by Porter Novelli, with input from federal public agencies as well as other profit and non-profit organizations. The CDC submitted questions for the survey in 2006 and 2007. The panel sample stemmed from the Epocrates Honor Panel http://www.epocates.com, consisting of 142,000 verified physicians [17]. A sample is randomly selected from the master database to match the American Medical Association (AMA) files in terms of age, sex, and region, which has information on all physicians in the United States, both members and non-members [18]. This sample was screened to include United States physicians practicing in individual, group, or hospital practices; those in an active practice; and those practicing for the last three years. In 2006, the goal was to recruit 1000 primary care physicians and 250 pediatricians. In 2007, the sample was expanded to also include 250 obstetricians and gynecologists (OB/GYN). Participating physicians received an honorarium, $\$ 30$ in 2006, and $\$ 45$ to $\$ 55$ in 2007, and were not required to participate in the survey and could opt out at anytime.

In 2006, the DocStyles survey contained 41 questions with multiple sub-parts, and in 2007, the survey had 69 questions with multiple sub-parts. There were fifteen CFS questions for both years of the survey. We measured knowledge by asking about CFS symptoms, and attitudes and beliefs by asking agreement to eight statements. Physicians were further asked if they had heard of CFS in the last six months, and if so, from what source the information originated, and if they had ever made a diagnosis of CFS. No personal identifiers were included in the survey and respondents could exit the web survey at anytime. Descriptive and frequency distributions, and chi-square statistics were reported in tables.

\section{Results}

\section{Conference Healthcare Providers}

Over a 21 month period, 4,065 healthcare providers at 13 conferences visited the CFS education booth. A total of 1,550 USB sticks were made available at all 13 conferences, and of these, 1,255 were requested for an $81 \%$ response rate. Characteristics of the sample are shown in Table 1. Physicians comprised about half $(\mathrm{n}=585)$ of the sample, nurse practitioners or physician assistants accounted for $30 \%(\mathrm{n}=378)$, occupational therapists $10 \%$ $(\mathrm{n}=124)$, and nurses $6 \%(\mathrm{n}=76)$. Most reported practicing in a hospital (26\%) or private practice $(27 \%)$.

Forty-one percent $(\mathrm{n}=512)$ of the sample reported ever given a diagnosis of CFS. Of these $71 \%(n=366)$ were physicians, $23 \%(\mathrm{n}=116)$ nurse practitioners or physician assistants, $2 \%(\mathrm{n}=10) \mathrm{PhD} /$ Masters, $3 \%$ nurses $(\mathrm{n}=13)$, $1 \%(\mathrm{n}=6)$ occupational therapists, and other $<1 \%(\mathrm{n}=1)$. The majority of physicians (35\%) were affiliated with private practice; nurse practitioners and physician assistants were primarily affiliated with hospitals (28\%); nurses with hospitals (60\%); and occupational therapists with hospitals (33\%). Practice setting was correlated with giving a diagnosis as $37 \%(n=186)$ of those who gave a diagnosis were affiliated with a private practice, $21 \%(\mathrm{n}=106)$ with a hospital, $20 \%(\mathrm{n}=103)$ with a group practice, and $8 \%(\mathrm{n}$ $=38$ ) with an academic setting.

Responses to the $9 \mathrm{KAB}$ questions were used in an exploratory principal components factor analysis and resulted in a four-factor best solution (eigenvalues greater than 1) that explained $73 \%$ of total variance (Table 2). Construct names were derived after reviewing content of the components from factor analysis: Attitude, Belief, Knowledge, and Perception. Attitude (20\% of the variance) included three statements: 1) "CFS as not a big problem as media suggests" 2) "People with CFS are just depressed" 3) and, "If people with CFS rest they will get better." Scores for this factor ranged from 3 to 21, with a high score indicating more negative attitudes towards CFS. Belief (19\% of the variance) included 2 items based on comparisons to other illnesses: 1) "CFS more difficult to treat and manage" 2) and, "CFS more difficult to diagnose." Scores for this factor ranged from 2 to 14, high scores indicating realistic beliefs about diagnosing and treating CFS. The Knowledge factor (18\% of the variance) included 2 items: 1) "Criteria for a CFS diagnosis are 6 months or more of fatigue, debilitating fatigue, and 4 of the 8 symptom criteria" and 2) "CFS can be diagnosed using 3 different questionnaires: the Medical Outcomes Survey Short Form-36 (SF-36), Multidimensional Fatigue Inventory (MFI), and CDC Symptom Inventory." Scores ranged from 2 to 14, high scores indicating a good working knowledge of CFS. Perception comprised the last factor and accounted for $15 \%$ of the variance. Perception included: 1) "Majority of people with CFS have a high 
Table 1: Characteristics of Healthcare Providers Conference sample $(n=1255)$.

\begin{tabular}{|c|c|c|}
\hline & Frequency & Percent \\
\hline \multicolumn{3}{|l|}{ Degree } \\
\hline MD/DO & 585 & 46.6 \\
\hline NP/PA & 378 & 30.1 \\
\hline RN & 76 & 6.1 \\
\hline OT & 124 & 9.9 \\
\hline $\mathrm{PhD} /$ Masters & 48 & 3.8 \\
\hline Other & 38 & 3.0 \\
\hline Missing & 6 & 0.5 \\
\hline \multicolumn{3}{|l|}{ Practice Setting } \\
\hline Hospital & 326 & 26 \\
\hline Private Practice & 331 & 26.4 \\
\hline Group Practice & 209 & 16.7 \\
\hline Academic & 105 & 8.4 \\
\hline Community & 98 & 7.8 \\
\hline Other & 167 & 13.3 \\
\hline Missing & 19 & 1.5 \\
\hline \multicolumn{3}{|c|}{ Ever given a CFS diagnosis } \\
\hline Yes & 512 & 40.8 \\
\hline No & 615 & 49 \\
\hline Not Applicable & 87 & 6.9 \\
\hline Missing & 41 & 3.3 \\
\hline
\end{tabular}

socio-economic status" and, 2) "Most people with CFS were competitive and driven before they got sick." Scores ranged from 2 to 14, with high scores indicating agreement of the statement. Reliability for each factor of Attitude, Belief, Knowledge, and Perception, as measured with standardized Cronbach's alpha were $0.66,0.81,0.73$, and 0.56 respectively.

Data for the conference healthcare providers KABs are shown in Table 3. Except for the statement "Majority of people with CFS were more competitive, driven to achieve, and compulsive before getting sick," in which $43 \%$ of respondents agreed, most healthcare providers were generally positive towards CFS attitudes and beliefs, and showed good levels of knowledge. Respondents disagreed that CFS is not as big of a problem as the media suggests and that the majority of people with CFS are from a higher socio-economic strata. Healthcare providers agreed with statements that compared to other illnesses CFS is more difficult to diagnose (70\%) and more difficult to treat and manage (72\%).

We examined the impact of ever having made a CFS diagnosis on KABs (Table 4). A past history of giving a
CFS diagnosis was significantly associated with the two Knowledge components, "Criteria for CFS" $(\mathrm{p}<0.001)$ and "CFS can be diagnosed using MFI, SF-36, CDC Symptom Inventory" $(\mathrm{p}<0.01)$; one Attitude statement "People with CFS are just depressed" ( $p<0.05)$; and the Belief factor "Compared to other illness CFS more difficult to diagnose $(\mathrm{p}<0.05)$ and treat and manage $(\mathrm{p}<$ 0.01 ).

\section{The relationship of KAB and Perception to education of healthcare providers}

Three scales, Attitude, Belief, and Knowledge, were associated with providers' education attainment (e.g. degree). Compared to nurses (mean $=8.1$ ), nurse practitioners and physician assistants, occupational therapists, and the $\mathrm{PhD} /$ Masters group had lower Attitude scores. There was no difference in Attitude between physicians and nurses. Physicians, nurse practitioners and physician assistants, occupational therapists, and $\mathrm{PhD} /$ Masters had statistically significantly higher Belief scores than nurses (mean = 9.1). In terms of Knowledge, physician and nurse practitioners and physician assistants had higher scores than nurses $($ mean $=9.2 ; \mathrm{p}<0.05)$. Compared to nurses, there 
Table 2: Constructs Resulted from Factor Analysis on CFS Knowledge, Attitudes, and Belief in Conference Healthcare Providers $(n=1255)$

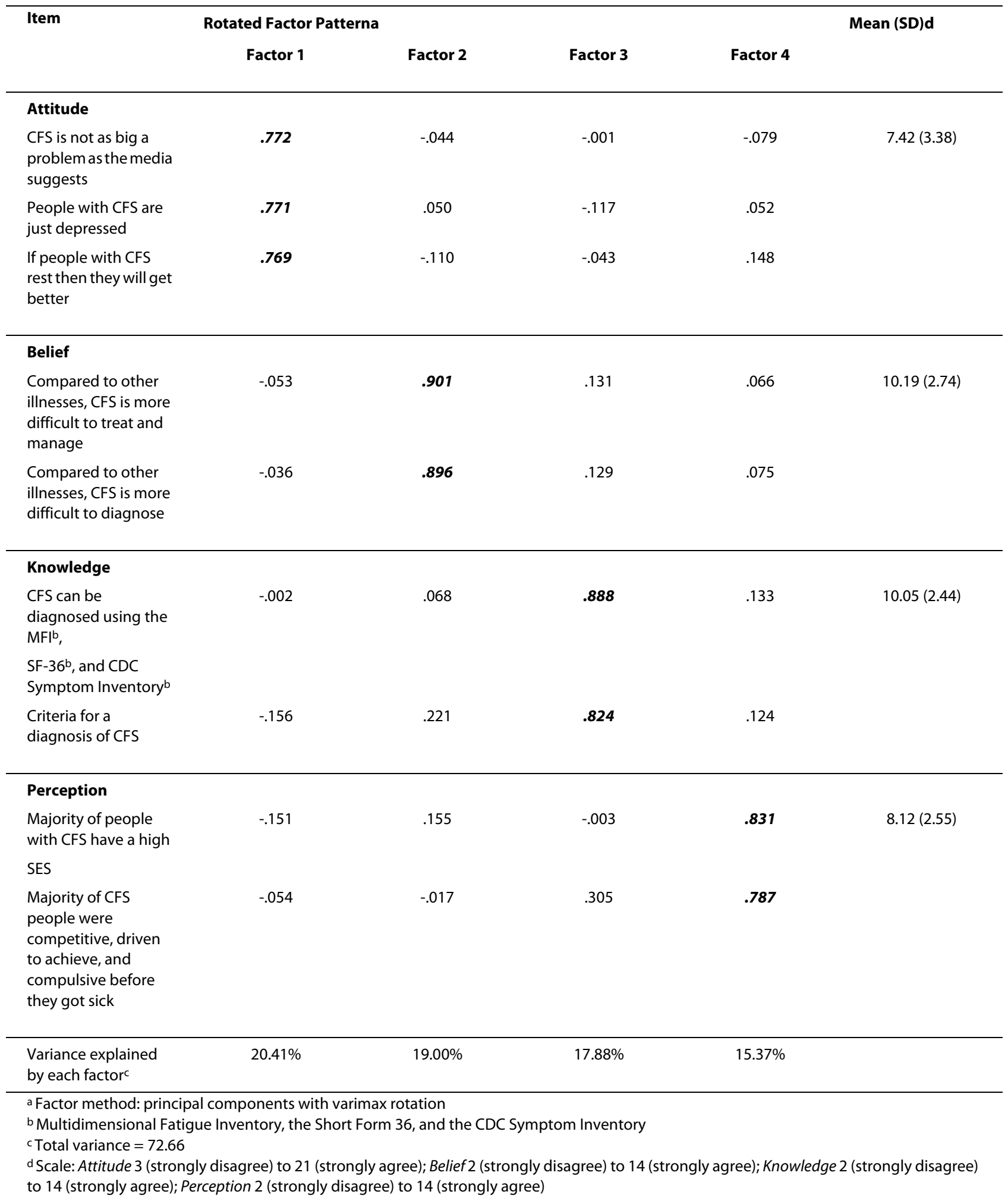


was no statistically significant difference in occupational therapists and the PhD/Masters group in terms of Knowledge. (See Additional file 1, Supplementary Table 1).

The relationship of KAB and Perception to practice setting of healthcare providers

Among the four scale scores, Attitude and Perception scores were associated with providers' practice settings. Compared to healthcare providers affiliated with the community, providers in hospitals had higher Attitude scores (mean $=7.8$ ) than those working in community settings $(\mathrm{p}=0.03)$ and providers in private practice also had higher Attitude scores than those working in community settings (mean $=6.9, \mathrm{p}=0.02$ ). Among all types of practice settings, only healthcare providers in all other practice setting group had a significant lower Perception score than healthcare providers in communities (mean
7.6 vs. 8.3, $\mathrm{p}=0.01$ ). (See Additional file 1, Supplementary Table 1).

The relationship of KAB and Perception to CFS diagnosis

Knowledge and Perception scores were associated with having diagnosed patients as CFS. Providers who had diagnosed CFS had a higher Knowledge scores than those who had never diagnosed the illness (mean 10.4 vs. 9.8, p $<0.0001)$, but their Perception scores were similar ( $\mathrm{p}=$ 0.89 ). Healthcare providers who were not applicable to give a CFS diagnosis had a lower Perception score than healthcare providers who never gave a CFS diagnosis before (mean 7.5 vs. 8.2, p = 0.03). (See Additional file 1, Supplementary Table 1).

After adjusting for education, practice setting, and CFS diagnosis, professional degree (e.g., MD, PA) remained significantly associated with Knowledge, Attitude, and

Table 3: Conference Healthcare Providers Knowledge, Attitudes, and Beliefs of CFS ( $n=1255)$.

\begin{tabular}{|c|c|c|c|c|}
\hline & $\begin{array}{l}\text { Agree }^{b} \\
\qquad \text { n (\%) }\end{array}$ & $\begin{array}{c}\text { Disagree } \\
\mathbf{n}(\%)\end{array}$ & $\begin{array}{c}\text { Neutral } \\
\text { n (\%) }\end{array}$ & Meana \\
\hline $\begin{array}{l}\text { CFS is not as big a } \\
\text { problem as media } \\
\text { suggests }\end{array}$ & $128(10)$ & $951(76)$ & 162 (13) & 2.48 \\
\hline $\begin{array}{l}\text { People with CFS are } \\
\text { just depressed }\end{array}$ & $147(12)$ & $946(75)$ & 157 (13) & 2.46 \\
\hline $\begin{array}{l}\text { If people with CFS rest } \\
\text { then they will get } \\
\text { better }\end{array}$ & $116(9)$ & $960(77)$ & 172 (14) & 2.48 \\
\hline $\begin{array}{l}\text { Compared to other } \\
\text { illnesses CFS is more } \\
\text { difficult to treat and } \\
\text { manage }\end{array}$ & $899(72)$ & $160(13)$ & $189(15)$ & 5.13 \\
\hline $\begin{array}{l}\text { Compared to other } \\
\text { illnesses CFS is more } \\
\text { difficult to diagnose }\end{array}$ & $881(70)$ & 194 (16) & 177 (14) & 5.06 \\
\hline $\begin{array}{l}\text { CFS can be diagnosed } \\
\text { using MFI, SF-36, and } \\
\text { CDC Symptom } \\
\text { Inventoryc }\end{array}$ & $615(49)$ & 159 (13) & $443(35)$ & 4.69 \\
\hline $\begin{array}{l}\text { Criteria for a CFS } \\
\text { diagnosis are fatigue } 6 \\
\text { months or longer, } \\
\text { debilitating fatigue, } \\
\text { and } 4 \text { of the } 8 \\
\text { symptom criteria }\end{array}$ & $948(75)$ & $113(9)$ & $184(15)$ & 5.36 \\
\hline $\begin{array}{l}\text { Majority of people with } \\
\text { CFS have a high SES }\end{array}$ & $371(30)$ & $453(36)$ & $418(33)$ & 3.84 \\
\hline $\begin{array}{l}\text { Majority of people with } \\
\text { CFS were competitive, } \\
\text { driven to achieve, and } \\
\text { compulsive before } \\
\text { getting sick }\end{array}$ & $541(43)$ & $360(28)$ & $331(26)$ & 4.28 \\
\hline
\end{tabular}


Table 4: Conference Healthcare Providers History of CFS diagnosis and CFS KABs $(n=1255)$.

\begin{tabular}{|c|c|c|c|c|c|c|c|}
\hline \multirow{2}{*}{$\begin{array}{l}\text { Have you } \\
\text { ever given a } \\
\text { diagnosis of } \\
\text { CFS n (\%) }\end{array}$} & \multirow[b]{2}{*}{ Agree $^{a}$} & \multirow{2}{*}{$\begin{array}{c}\text { Yes } \\
\text { Disagree }\end{array}$} & \multirow[b]{2}{*}{ Neutral } & \multicolumn{3}{|c|}{ No } & \multirow[b]{2}{*}{$x^{2}$} \\
\hline & & & & Agree & Disagree & Neutral & \\
\hline $\begin{array}{l}\text { Criteria for } \\
\text { CFS } \\
\text { diagnosis: } \\
\text { fatigue }>6 \\
\text { months and } 4 \\
\text { of } 8 \text { symptom } \\
\text { criteria }\end{array}$ & $434(85)$ & $45(9)$ & $33(6)$ & $425(70)$ & $59(10)$ & $122(20)$ & $45.50^{* * *}$ \\
\hline $\begin{array}{l}\text { CFS can be } \\
\text { diagnosed } \\
\text { using MFI, SF- } \\
36 \text {, and CDC } \\
\text { Symptom } \\
\text { Inventoryc }\end{array}$ & $284(57)$ & $58(12)$ & $158(32)$ & $278(47)$ & 85 (14) & 231 (39) & $10.87^{* *}$ \\
\hline $\begin{array}{l}\text { Majority of } \\
\text { people with } \\
\text { CFS were } \\
\text { competitive, } \\
\text { driven to } \\
\text { achieve, } \\
\text { compulsive } \\
\text { before sick }\end{array}$ & $227(45)$ & $140(28)$ & $134(27)$ & $262(43)$ & $174(29)$ & $168(28)$ & 0.41 \\
\hline $\begin{array}{l}\text { CFS is not as } \\
\text { big a } \\
\text { problem as } \\
\text { media } \\
\text { suggests }\end{array}$ & $56(11)$ & $392(77)$ & $60(12)$ & $59(10)$ & $459(76)$ & $90(15)$ & 2.14 \\
\hline $\begin{array}{l}\text { Majority of } \\
\text { people with } \\
\text { CFS have a } \\
\text { high SES }\end{array}$ & $159(31)$ & 187 (37) & $161(32)$ & $183(30)$ & 207 (34) & $218(36)$ & 2.14 \\
\hline $\begin{array}{l}\text { If people with } \\
\text { CFS rest then } \\
\text { they will get } \\
\text { better }\end{array}$ & $55(11)$ & $390(76)$ & $66(13)$ & $53(9)$ & 470 (77) & $88(14)$ & 1.72 \\
\hline $\begin{array}{l}\text { People with } \\
\text { CFS are just } \\
\text { depressed }\end{array}$ & $70(14)$ & $386(76)$ & $54(11)$ & $59(10)$ & $464(76)$ & 89 (15) & $7.45^{*}$ \\
\hline $\begin{array}{l}\text { Compared to } \\
\text { other } \\
\text { illnesses CFS } \\
\text { more difficult } \\
\text { to diagnose }\end{array}$ & $344(67)$ & $94(18)$ & $73(14)$ & 449 (73) & 79 (13) & $85(14)$ & $6.91^{*}$ \\
\hline $\begin{array}{l}\text { Compared to } \\
\text { other } \\
\text { illnesses CFS } \\
\text { more difficult } \\
\text { to treat/ } \\
\text { manage }\end{array}$ & 391 (77) & $64(13)$ & $54(11)$ & $428(70)$ & $74(12)$ & 109 (18) & $11.76^{* *}$ \\
\hline
\end{tabular}

${ }^{*} \mathrm{p}<0.05 ;{ }^{* *} \mathrm{p}<0.01 ; * * * \mathrm{p}<0.001$

aAgree $=$ values 5, 6, 7; Disagree $=$ values 1, 2, 3; Neutral $=$ value 4

c Multidimensional Fatigue Inventory (MFI), Medical Outcomes Survey Short Form-36 (SF-36), 
Belief, but diagnosis did not. After the adjustment, practice setting remained only significantly associated with Attitude.

\section{DocStyles Physicians}

The 2006 DocStyles study collected responses from 1,455 physicians (response rate 61\%). However, the final sample size was 1,250 due to a random data storage error that occurred during an overnight backup procedure in which the programmer accidently overwrote the data. No particular demographics were affected as one days' worth of data (205 physicians) was lost but the original quotas were obtained. In 2007, 1,500 physicians completed surveys for a $48 \%$ response rate. Demographics for both study years are displayed in Table 5.

DocStyles physicians were asked, "Before today, have you ever heard of chronic fatigue syndrome (CFS)?" In 2006, 97\% $(n=1212)$ responded yes as did $96 \%(n=1441)$ in 2007. Table 6 shows the data in response to the 7 CFS opinion statements. When asked, "There is enough information available to clinicians to diagnosis CFS," 25\% ( $\mathrm{n}=$ $308)$ agreed in 2006 and $30 \%(n=448)$, in 2007 . In both surveys $20 \%$ of physicians agreed with the statement "I believe CFS is only in the patient's head." For the statement, "There are several treatment options available for people with CFS," $43 \%(n=534)$ agreed with the statement in 2006 and 49\% ( $n=738)$ in 2007. Physicians were also queried about quality of life for both CFS patients and their caregivers or families. When asked, "CFS can impair a person's quality of life," $90 \%(n=1353)$ in the 2006 sample, and $87 \%(n=1088)$ in the 2007 sample agreed. As for the question, "CFS can impair the quality of life for the patient's family or caregiver," $86 \%(\mathrm{n}=1076)$ in 2006 , and $89 \%(n=1341)$ in 2007 , agreed.

We further examined how a history of making a CFS diagnosis influences attitudes and beliefs of CFS (Table 7). In $2006,46 \%(\mathrm{n}=571)$ of DocStyles physicians reported having diagnosed CFS and 2007, 36\% $(\mathrm{n}=536)$ reported ever making a diagnosis of CFS (see Table 5). In both study years, physicians who had ever made a diagnosis of CFS had significantly different opinions as compared to those physicians who had not made a diagnosis. For example, in 2006, 36\% of physicians who reported giving a diagnosis agreed that enough information was available to diagnose CFS compared to $15 \%$ who had not given a diagnosis. Physicians were less likely to think that CFS was in a patient's head if he/she had given a diagnosis ( $\mathrm{p}<0.01$ in 2006; $\mathrm{p}<0.01$ in 2007).

Physicians were asked to identify symptoms of CFS (Table 8). For each year, the majority of physicians correctly recognized symptoms associated with CFS and responded in the negative regarding symptoms not associated with CFS. The 4 most correctly identified symptoms (unexplained fatigue, unrefreshing sleep, impaired memory, and muscle or joint pain) were endorsed by over $80 \%$ of physicians.

During the 2006 DocStyles survey, 20\% ( $n=251$ ) participants indicated they have read or heard something concerning in the past few months, as did $16 \%(\mathrm{n}=233)$ of 2007 DocStyles participants (Table 9). Those who said yes were further queried as to the source and the top 3 resources for both years were professional journals, the Internet, and continuing education programs.

\section{Discussion}

We found parallel findings regarding healthcare providers' awareness, knowledge, and diagnosis concerning CFS in both the Conference Healthcare Providers and DocStyles Physicians samples. Over 96\% of primary care physicians, pediatricians, and obstetrics/gynecologists in the DocStyles survey reported ever hearing about CFS. In both studies, physicians reported giving a diagnosis of CFS: $64 \%$ of conference attendee physicians, and an average of $41 \%$ of DocStyles physicians.

A history of prior CFS diagnosis by a healthcare provider or physician impacts the knowledge, attitudes, beliefs, and perceptions of how these professionals view CFS. Forty-one percent of Conference Healthcare Providers reported making a diagnosis of CFS and these respondents were more likely than those who had not made a diagnosis to have a better understanding of the complexities associated with CFS. Similarly, in 2006 and 2007, 46\% and 36\% of DocStyles Physicians reported giving a diagnosis of CFS and yet $20 \%$ of this sample agreed with the statement that "I believe that CFS is all in a patient's head." However, those physicians who had made a diagnosis were significantly less likely to agree with this statement, $66 \%$ in 2006 and $85 \%$ in 2007 , compared to those who did not make a diagnosis, $39 \%$ and $64 \%$. These findings are similar to those by Sheeres et al, who found that the more informed physicians are towards CFS, the better the knowledge, attitudes, and beliefs associated with CFS [13].

While additional research is needed to explore why a small percent of physicians who gave a diagnosis still agreed that "CFS is all in the patient's head," one hypothesis is that when physicians have a troublesome experience with a patient, it may skew their attitudes towards CFS and yet allow the diagnostic process to proceed. It must be noted that physicians may have difficulties with a CFS not because of the patient per say, but because the physician finds the diagnostic and management process difficult to navigate.

Physicians in the Conference Healthcare Providers sample had the highest mean score on knowledge compared to nurses, nurse practitioners and physician assistants, occupational therapists, and $\mathrm{PhD} /$ Masters. In terms of knowledge, more than $80 \%$ of physicians in the DocStyles 
Table 5: Demographics of DocStyles Physicians.

\begin{tabular}{|c|c|c|c|c|c|}
\hline & \multicolumn{2}{|c|}{2006} & \multicolumn{3}{|c|}{2007} \\
\hline & $\begin{array}{l}\text { PCPa } \\
\quad n(\%)\end{array}$ & $\begin{array}{l}\text { PED }^{\mathbf{b}} \\
\quad \text { n (\%) }\end{array}$ & $\begin{array}{l}\text { PCP } \\
\text { n (\%) }\end{array}$ & $\begin{array}{l}\text { PED } \\
\text { n (\%) }\end{array}$ & $\begin{array}{l}\text { OB/GYNc } \\
\text { n (\%) }\end{array}$ \\
\hline Sample size & $1000(80)$ & $250(20)$ & $1000(66.6)$ & 250 (16.6) & 250 (16.6) \\
\hline \multicolumn{6}{|l|}{ Sex } \\
\hline Male & $720(72)$ & $127(51)$ & $690(69)$ & $167(67)$ & $100(40)$ \\
\hline Female & $280(28)$ & $122(49)$ & $310(31)$ & $83(33)$ & $150(60)$ \\
\hline Age (average) & 44.2 & 45.0 & 44.1 & 44.4 & 45.2 \\
\hline $\begin{array}{l}\text { Years in Practice } \\
\text { (average) }\end{array}$ & 13.7 & 14.9 & 13.5 & 14.9 & 14.5 \\
\hline \multicolumn{6}{|l|}{ Region } \\
\hline $\mathrm{NE}$ & $240(24)$ & $40(16)$ & $240(24)$ & $71(29)$ & $67(27)$ \\
\hline North Central & $220(22)$ & $75(30)$ & $250(25)$ & $52(21)$ & $57(23)$ \\
\hline South & $320(32)$ & $80(32)$ & $300(30)$ & $75(30)$ & $85(34)$ \\
\hline West & $220(22)$ & $52(21)$ & $210(21)$ & $52(21)$ & $42(17)$ \\
\hline $\begin{array}{l}\text { Number of } \\
\text { patients per week } \\
\text { (average) }\end{array}$ & 121.0 & 124.8 & 123.0 & 109.5 & 119.6 \\
\hline $\begin{array}{l}\text { Number of } \\
\text { physicians in } \\
\text { group (average) }\end{array}$ & 12.8 & 8.9 & 18.0 & 11.6 & 12.0 \\
\hline $\begin{array}{l}\text { Have you ever } \\
\text { diagnosed a } \\
\text { patient with CFS? }\end{array}$ & $521(52)$ & $50(20)$ & $471(47)$ & $41(16)$ & $24(10)$ \\
\hline
\end{tabular}

survey correctly identified the 4 most common CFS symptoms (unexplained fatigue, unrefreshing sleep, impaired memory or concentration, and muscle or joint pain). U.S. physicians as a whole are clearly aware of CFS, knowledgeable about CFS symptoms, and around half have given a diagnosis.

Of all healthcare providers, nurses had the lowest mean knowledge compared to physicians, physician assistants, nurse practitioners, occupational therapists, and the $\mathrm{PhD} /$ Masters group. Providers who reported ever giving a diagnosis of CFS scored significantly higher on the knowledge factor compared to those who had not although this association was not statistically significant after the adjustment of physicians' degree and practice setting.

When examining beliefs towards CFS diagnosis and management, physicians, physician assistants, nurse practitioners, occupational therapists, and the $\mathrm{PhD} /$ Masters group all scored significantly higher than nurses, which indicates that nurses included in our sample did not have had an informed view of the diagnostic and management issue associated with CFS. Physicians and nurses had significantly higher scores on the attitude factor as compared to nurse practitioners, physician assistants, occupational therapists, and the $\mathrm{PhD} /$ Masters group, which indicates a more negative attitude towards CFS. However, all means in the attitudes factor fell between the $25^{\text {th }}$ and $50^{\text {th }}$ percentile indicating an overall low negative attitude to CFS among the sample. In the Perception score, physicians had the lowest mean score indicating a good perception of CFS in the population whereas nurses, nurse practitioners, and physician assistants had higher scores although not statistically significant.

Our finding that nurses in the Conference Healthcare Providers sample harbored slightly more negative attitudes and beliefs of CFS and were also less knowledge supports a recent study by Chew-Graham et al, which found that nurses in the United Kingdom had "limited knowledge and experience with clinical features of the illness, its etiology and appropriate management strategies" [[19], p 8]. Nurses in that study were aware of CFS, yet 
Table 6: DocStyles Physicians CFS Knowledge, Attitudes, and Beliefs.

\begin{tabular}{|c|c|c|c|c|c|c|}
\hline & \multicolumn{3}{|c|}{$2006^{a}$} & \multicolumn{3}{|c|}{$2007^{b}$} \\
\hline & & n (\%) & & & n (\%) & \\
\hline & Agree & Disagree & Don't know & Agree & Disagree & Don't know \\
\hline $\begin{array}{l}\text { Emerging } \\
\text { medical } \\
\text { research is } \\
\text { uncovering } \\
\text { complexities } \\
\text { of CFS }\end{array}$ & $506(40)$ & $233(19)$ & $511(41)$ & $745(50)$ & $383(25)$ & $372(25)$ \\
\hline $\begin{array}{l}\text { Enough } \\
\text { information } \\
\text { available to } \\
\text { clinicians to } \\
\text { diagnose CFS }\end{array}$ & $308(25)$ & $604(48)$ & $338(27)$ & $448(30)$ & $876(58)$ & $176(12)$ \\
\hline $\begin{array}{l}\text { CFS can impair } \\
\text { a person's } \\
\text { quality of life }\end{array}$ & $1088(87)$ & $27(2)$ & $135(11)$ & $1353(90)$ & $79(5)$ & $68(5)$ \\
\hline $\begin{array}{l}\text { I believe CFS is } \\
\text { only in the } \\
\text { patient's head }\end{array}$ & $247(20)$ & $637(51)$ & $366(29)$ & $289(19)$ & $1077(72)$ & $134(9)$ \\
\hline $\begin{array}{l}\text { If diagnosed } \\
\text { and treated } \\
\text { within first five } \\
\text { years, CFS } \\
\text { patients are } \\
\text { more likely to } \\
\text { get better }\end{array}$ & $383(31)$ & $214(17)$ & $653(52)$ & $592(40)$ & $394(26)$ & $514(34)$ \\
\hline $\begin{array}{l}\text { There are } \\
\text { several } \\
\text { treatment } \\
\text { options } \\
\text { available for } \\
\text { people with } \\
\text { CFS }\end{array}$ & $543(43)$ & $300(24)$ & 407 (33) & $738(49)$ & $463(31)$ & $299(20)$ \\
\hline $\begin{array}{l}\text { A diagnosis of } \\
\text { CFS can inhibit } \\
\text { a patient's } \\
\text { motivation to } \\
\text { get better }\end{array}$ & $685(55)$ & $208(16)$ & $357(29)$ & $849(57)$ & $458(30)$ & $193(13)$ \\
\hline $\begin{array}{l}\text { CFS can impair } \\
\text { quality of life } \\
\text { for the } \\
\text { patient's } \\
\text { family or } \\
\text { caregiver }\end{array}$ & $1076(86)$ & $31(3)$ & $143(11)$ & $1341(89)$ & $82(6)$ & $77(5)$ \\
\hline
\end{tabular}

many reported receiving little training concerning the illness and this may account for the discrepancy in awareness versus education. In fact, many CFS education programs target healthcare providers who either diagnose CFS (e.g. physicians or nurse practitioners) or those who assist in management modalities (e.g. cognitive behavioral therapist or occupational therapists). While further research is warranted, CFS education programs aimed at nurses that provide information on the clinical aspects of the illness as well as overall management strategies may be beneficial.

In the United States less than $20 \%$ of persons with CFS receive a diagnosis and yet both the Conference Healthcare Providers and DocStyles Physicians respondents 
Table 7: DocStyles Physicians History of CFS Diagnosis and CFS KABs.

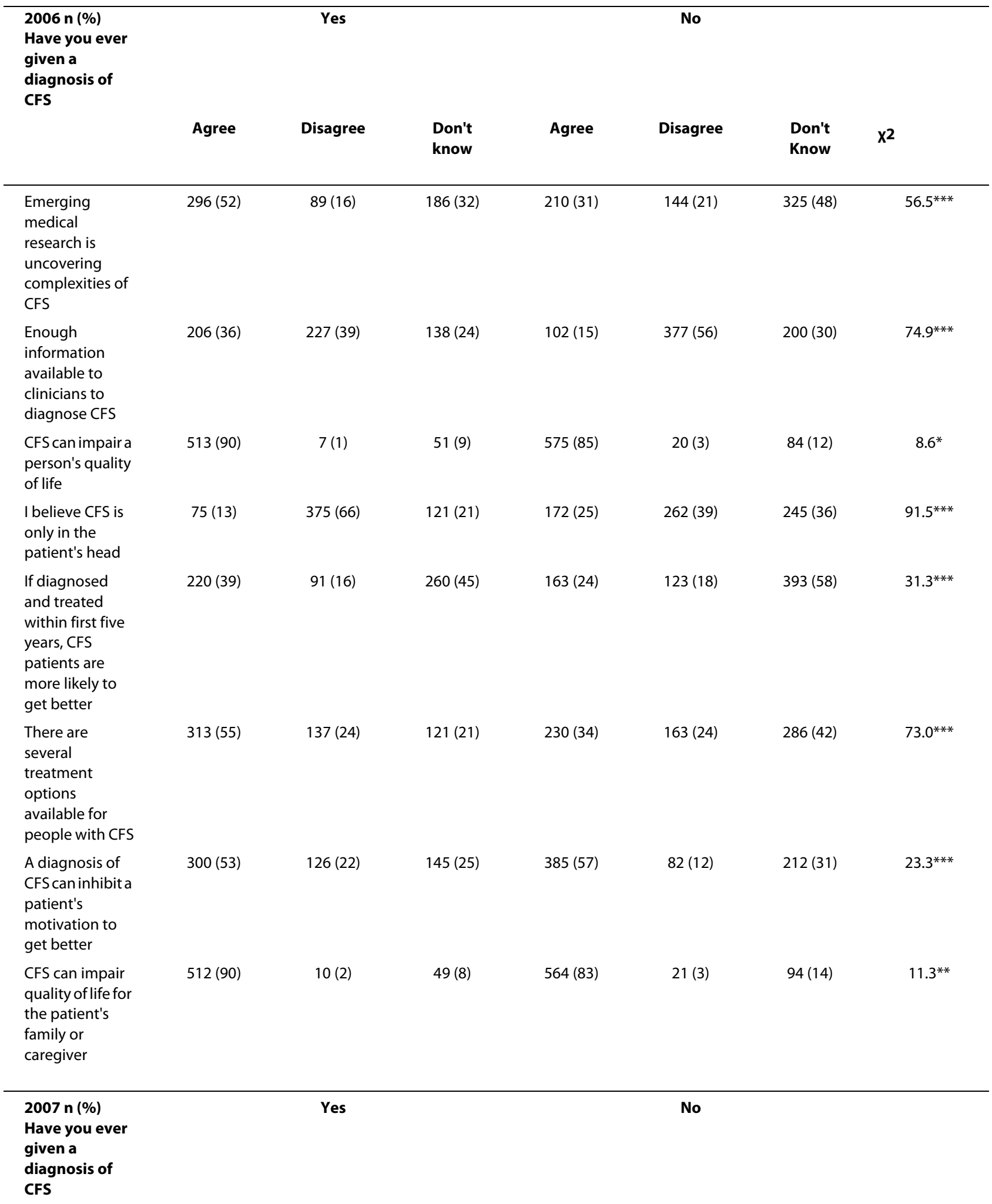


Table 7: DocStyles Physicians History of CFS Diagnosis and CFS KABs. (Continued)

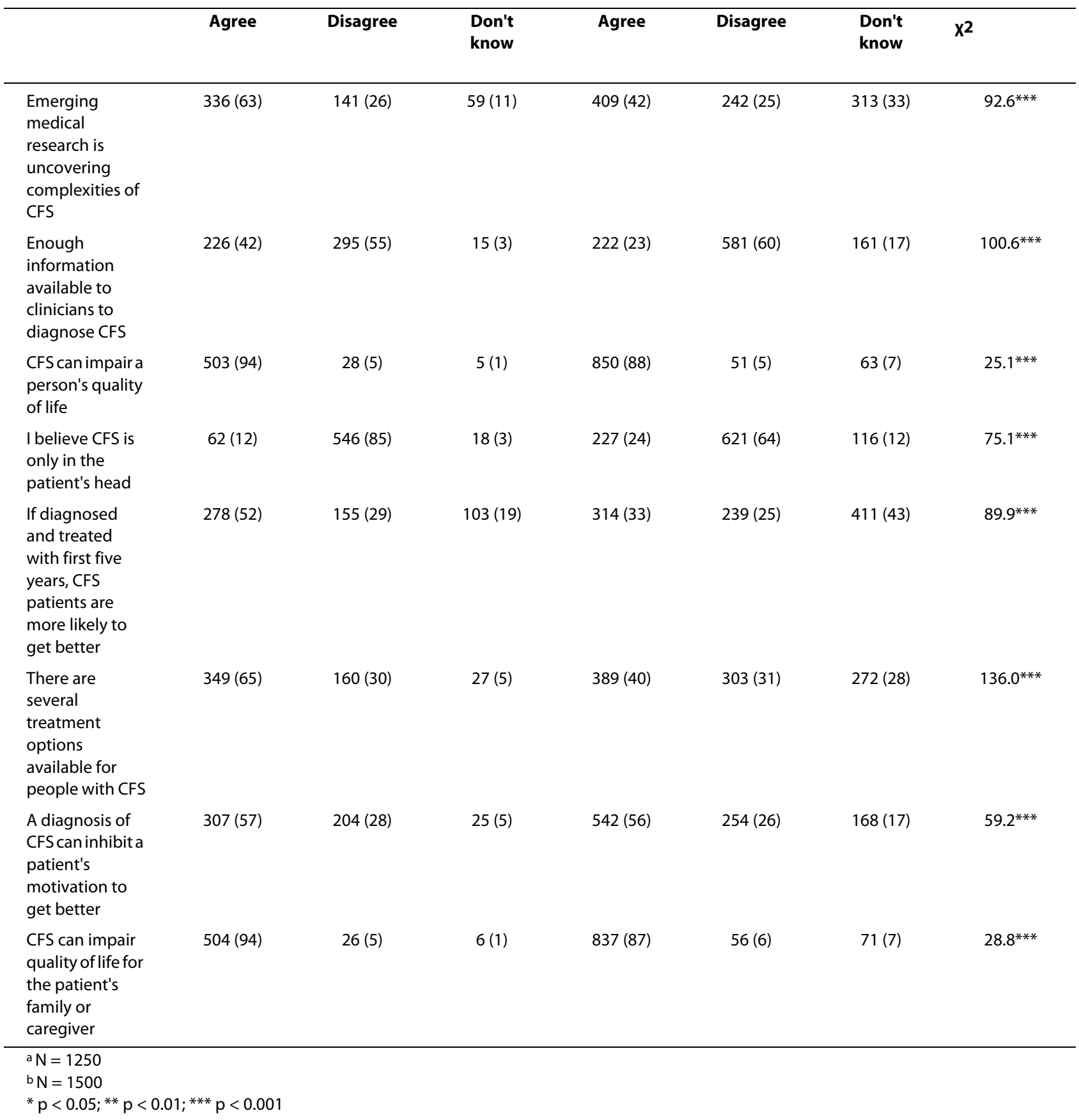

reported that an average of $41 \%$ of had diagnosed CFS. This finding suggests that persons with CFS may not be aware that assistance is available in the healthcare system in terms of CFS diagnosis and management. It is understandable that patients may delay care because of insurance issues or perceived barriers to healthcare access. Patients need encouragement to seek medical care for CFS symptoms and not concentrate on perceived attitudes and beliefs of providers. However, coupled with this approach, healthcare providers need further guidance on the clinical evaluation, diagnosis, and management strategies for CFS.

When physicians in the DocStyles survey responded to quality of life statements, over $86 \%$ of the sample agreed that CFS affects both the patient and the patient's family or caregiver quality of life. This confirms that U.S. physicians recognize the impact of CFS on patients and families. Contrary to existing beliefs, physicians in this sample showed compassion and understanding about CFS issues. In this same study physicians were asked about diagnostic 
information and treatment options for CFS. Fewer than $30 \%$ agreed that enough information was available to make a CFS diagnosis. In terms of treatment options, less than half of physicians agreed there were treatment options for CFS.

The disparity in agreement between acknowledgment that CFS affects quality of life, a high level of awareness, and the ability to recognize the symptoms of CFS versus the inability to recognize that diagnostic and treatment guides are available, point to the need for education programs that provide greater focus on the clinical evaluations and management options and less on raising CFS awareness. Data from both samples demonstrate that while a small percent of healthcare providers are skeptical of CFS and express negative attitudes, the majority of respondents recognize CFS as an illness and understand the impacts it has on society. While physicians in both samples showed high levels of CFS knowledge and appropriate attitude scores, they also demonstrated confusion in how to treat and manage CFS. Future CFS research and educational interventions should incorporate evidencebased behavioral theories with constructs of knowledge, attitudes, and beliefs in the development of programs.

Physicians in the DocStyles survey reported that professional journals, the Internet, and continuing education programs as the top three sources in which they had heard or read about CFS in the past few months. Indeed, the identification of appropriate dissemination and communication channels is extremely important to tailoring information to selected target audiences [20], and so should be taken more advantage of to have an even greater impact on healthcare professionals' awareness of CFS.

\section{Strengths and Limitations}

A strength of the current research is the use of diverse research methods. It is common in social science research to combine convenience and probability sampling in order to reduce costs and yet strengthen the rigor of the study design. Other strengths of the study include sufficient sample sizes and the use of the factor analysis in the first sample to assess both reliability and construct validity of the survey.

This research has several limitations. In the Conference Healthcare Providers sample, the subjects were selected using convenience sampling, whereas in the second sample physicians were randomly selected proportional to the physician demographic database of the American Medical Association in terms of age, sex, and region. However, Singleton et al state that "while one should be mindful of [weaknesses] it would be a mistake to rule out nonprobability sampling," particularly "in the early stages of investigating a problem, when the objective is to become more informed about the problem itself." [[21], p 159].

A second limitation is the potential for selection bias in the Conference Healthcare Providers sample. While advertisements invited all healthcare providers at conferences to visit the CFS education booth and receive a free USB stick, there is the potential bias of persuasive efforts that those persons familiar with CFS or those who wanted a free USB stick, may have been more likely to visit the booth and participate in the survey. A third limi-

Table 8: Percent of DocStyles Physicians Recognizing CFS symptoms.

\begin{tabular}{lcc}
\hline Symptoms & & Physicians \\
& & $\mathbf{2 0 0 7}$ \\
& $\mathbf{2 0 0 6}$ & $\mathbf{n}(\%)$ \\
Unexplained fatigue not improved by rest & $\mathbf{n}(\%)$ & $1384(92)$ \\
Unrefreshing sleep & $1179(94)$ & $1291(88)$ \\
Impaired memory or concentration & $1113(89)$ & $1195(80)$ \\
Muscle or joint pain & $1025(82)$ & $1194(80)$ \\
Headaches & $1049(84)$ & $937(63)$ \\
Tender lymph nodes & $848(68)$ & $660(44)$ \\
Sore throat & $533(43)$ & $519(35)$ \\
Vomiting & $472(38)$ & $90(6)$ \\
Excessive thirst & $64(5)$ & $87(6)$ \\
Rash on trunk or extremities & $66(5)$ & $77(5)$ \\
Blood in urine & $64(5)$ & $16(1)$
\end{tabular}

Italicized symptoms are CFS symptoms

2006 sample $n=1250$

2007 sample $n=1500$ 
Table 9: Source of DocStyles Physicians Reading or Hearing about CFS in Past Few Months.

\begin{tabular}{lcc}
\hline Source & & Physicians \\
& & $\mathbf{2 0 0 7}$ \\
& $\mathbf{2 0 0 6}(\%)$ & $(60)$ \\
\hline Professional journals & $\mathbf{n}(\%)$ & $(37)$ \\
Internet & $153(61)$ & $(27)$ \\
Continuing education programs & $96(38)$ & $(15)$ \\
Consumer magazines & $67(27)$ & $(14)$ \\
Newspapers & $50(20)$ & $(12)$ \\
Professional meeting & $40(16)$ & $(11)$ \\
Television & $35(14)$ & $(3)$ \\
Radio & $40(16)$ & $(1)$ \\
Billboards & $25(10)$ & $(<1)$ \\
Photo Exhibit & $5(2)$ & \\
\hline
\end{tabular}

2006 sample $n=251$

2007 sample $\mathrm{n}=233$

tation is that physicians who participated in the DocStyles sample, a web-based survey, were more likely to be younger and more sophisticated with computers. The average age among this population was 44.6 years of age, which supports the view that the sample consisted of a younger group of physicians. Younger physicians may view CFS differently than older physicians as it is more likely that younger physicians have encountered CFS in medical school, residency programs, or continuing medical education. Physicians who use computers in their practice may differ from other practicing physicians by living or practicing in a more urban or metropolitan area as compared to those in rural areas. Finally, the questionnaire in the DocStyles sample was not assessed for reliability or validity.

\section{Conclusion}

The findings begin to fill a gap in the evidence-base concerning knowledge, attitudes, beliefs, and perceptions of U.S. healthcare providers concerning CFS. However, further research concerning CFS KABs among healthcare providers and physicians is needed to assist in developing and delivering educational interventions. Importantly, participants in both samples expressed similar opinions in terms of knowledge, attitudes, and beliefs.

\section{Additional material}

Additional file 1 Supplementary Table 1. Bivariate Associations of CFS Knowledge, Attitudes, Beliefs, and Perception Domain Scores.

\section{Authors' contributions}

DB drafted the manuscript, participated in study coordination, and helped to conceive the study. FF coordinated parts of the study design and helped to draft the manuscript. JML analyzed the data and contributed to drafting the manuscript. WR conceived of the study, participated in study coordination and helped to draft the manuscript. All authors read and approved the final manuscript.

\section{Acknowledgements}

The findings and conclusions in this report are those of the authors and do not necessarily represent the views of the funding agency

\section{Author Details}

'Division of Viral and Rickettsial Diseases, Centers for Disease Control and Prevention, Atlanta, GA, USA and 'Division of Health Communication and Marketing, Centers for Disease Control and Prevention, Atlanta, GA, USA

Received: 8 October 2009 Accepted: 21 April 2010

Published: 21 April 2010

\section{References}

1. Fukuda K, Strauss SE, Hickie I, Sharpe MC, Dobbins JG, Komaroff A: The chronic fatigue syndrome: a comprehensive approach to its definition and study. Ann Int Med 1994, 121:953-959.

2. Coyne JC, Thompson R, Klinkman MS, Nease DE: Emotional disorders in primary care. Journal of Consulting and Clinical Psychology 2002, 70(3):798-809.

3. Rief W, Martin A, Rauh E, Zech T, Bender A: Evaluation of General Practitioners' Training: How toe manage patients with unexplained physical symptoms. Psychosomatics 2006, 47:304-311.

4. Larun L, Malterud K: Identity and coping experiences in Chronic Fatigue Syndrome: A synthesis of qualitative studies. Patient Education and Counseling 2007, 69:20-28.

5. Lin JM, Brimmer DJ, Boneva RS, Jones JF, Reeves WC: Barriers to healthcare utilization in fatiguing illness: a population-based study in Georgia. BMC Health Services Research 2009, 9:13.

6. Nater UM, Lin JM, Maloney EM, Jones JF, Tian H, Raison CL, Reeves WC, Heim C: Psychiatric comorbidity with affective and anxiety disorders in chronic fatigue syndrome - a population-based study. Psychosom Med 2009, 71(5):557-65. Epub 2009 May 4

\section{Competing interests}

The authors declare that they have no competing interests. 
7. Wyshak G, Barsky A: Satisfaction with and effectiveness of medical care in relation to anxiety and depression - patient and physician ratings compared. General Hospital Psychiatry 1995, 17:108-114.

8. Solomon L, Reeves WC: Factors influencing the diagnosis of chronic fatigue syndrome. Arch Intern Med 2004, 164:2241-2245.

9. Reeves WC, Jones JF, Maloney E, Heim C, Hoaglin DC, Boneva RS, Morrissey M, Devlin R: Prevalence of chronic fatigue syndrome in metropolitan, urban, and rural Georgia. Population Health Metrics 2007, 5:5.

10. Raine R, Carter S, Sensky T, Black N: General practitioners' perceptions of chronic fatigue syndrome and beliefs about its management, compared with irritable bowel syndrome: qualitative study. BMJ 2004, 328(7452):1354-7. Epub 2004 May 28

11. Bowen J, Pheby D, Charlett A, McNulty C: Chronic Fatigue Syndrome: a survey of GPs' attitudes and knowledge. Family Practice 2005, 22:389-393.

12. Thomas MA, Smith AP: Primary healthcare provision and Chronic Fatigue Syndrome: a survey of patients' and General Practitioners' beliefs. BMC Family Practice 2005, 6:49.

13. Scheeres $K$, Wensing M, Mes C, Bleijenberf G: The impact of informational interventions about cognitive behavioral therapy for chronic fatigue syndrome on GPs referral behavior. Patient Education and Counseling 2007, 68:29-32.

14. Steven I, McGrath B, Qureshi F, Wong C, Chern I, Pearn-Rowe B: General practitioners' belief, attitudes and reported actions towards chronic fatigue syndrome. Austrailian Family Physician 2000, 29(1):80-85.

15. Lu T, Torres-Harding S, Jason L: The effectiveness of early educational intervention in improving future physicians' attitudes regarding CFS/ FM. Journal of Chronic Fatigue Syndrome 2007, 14(2):25-30.

16. Suhr D: Reliability, exploratory, and confirmatory factor analysis for the scale of athletic priorities. Paper presented at the SUGI, Seattle, Washington; 2003

17. Eopcrates, 2006 and 2007 [http://www.epocrates.com/services/ marketresearch

18. Gust D, Weber D, Weintraub E, Kennedy A, Soud F, Burns A: Physicians who do and do not recommend children get all vaccinations: Journal of Health Communication.

19. Chew-Graham C, Dixon R, Shaw JW, Smyth N, Lovell K, Peters S: Practice nurses' views of their roles in the management of chronic fatigue syndrome/myalagic encephalitis: a qualitative study. BMC Nursing 2009, 8:2.

20. Kotler P, Lee NR: Social Marketing Influencing Behaviors for Good Los Angles: Sage Publications; 2008.

21. Singleton R, Straits B, Straits MM: Approaches to Social Research New York: Oxford University Press; 1993.

\section{Pre-publication history}

The pre-publication history for this paper can be accessed here: http://www.biomedcentral.com/1471-2296/11/28/prepub

\section{Submit your next manuscript to BioMed Central} and take full advantage of:

- Convenient online submission

- Thorough peer review

- No space constraints or color figure charges

- Immediate publication on acceptance

- Inclusion in PubMed, CAS, Scopus and Google Scholar

- Research which is freely available for redistribution

Submit your manuscript at www.biomedcentral.com/submit
C Biomed Central 